\title{
Construction of “Interactive” English Translation Teaching Model Based on Data-Driven Learning
}

\author{
Yabin Huang $(\mathbb{D}$ \\ Humanities and Social Sciences College, Heilongjiang Bayi Agricultural University, Daqing 163319, China \\ Correspondence should be addressed to Yabin Huang; huanghyb365@byau.edu.cn
}

Received 10 December 2021; Revised 28 December 2021; Accepted 29 December 2021; Published 31 January 2022

Academic Editor: Xin Ning

Copyright (c) 2022 Yabin Huang. This is an open access article distributed under the Creative Commons Attribution License, which permits unrestricted use, distribution, and reproduction in any medium, provided the original work is properly cited.

\begin{abstract}
With the growth of international trade, there is a greater demand for people with a diverse professional background and a high level of foreign language translation skills. This thesis covers the fundamental concepts and evolution of data-driven learning, wellknown data-driven learning systems, common statistical parameters and analytical statistical methods of data-driven learning, and commonly used data-driven learning indexing software and its basic functions. A basic knowledge outline and data-driven learning thinking method are provided. Although English translation is widely used, there are still many flaws in professional training. In response to the current situation in which college English translation teaching is difficult to adapt to new requirements of college English teaching and talent training, it is proposed to combine multimedia technology and corpus, as well as support constructivist learning theory, data-driven learning theory, and autonomous learning theory, to create a "data-driven Learning (DLL) college English translation teaching model," beginning with the teaching materials, teaching objectives, and a "data-driven Learning (DLL) college English translation teaching model," starting from the teaching materials, teaching the impact of the model on college students' translation learning. The results of the experiments show that this mode is associated with a significant improvement in students' translation learning abilities. This model is shown to be effective when used in college English translation classes.
\end{abstract}

\section{Introduction}

At present, the focus of English translation teaching is to cultivate students' thinking skills, improve their theoretical knowledge and skills, and apply them reasonably in practice and solve problems. The traditional concept of teaching still occupies the entire teaching mode, and practical application and theoretical teaching cannot promote each other. In the actual teaching process, workers fail to pay attention to the teaching objectives and training content of translation courses, resulting in students now only attaching importance to written language knowledge but ignoring its practical applicability. The ability of students to innovate and solve practical problems is not only important for other disciplines but also for translation work. Therefore, in the arrangement of teaching and learning, students should not only master the basic theories in the textbook but also study the culture and language habits of the two countries in depth
[1]. Therefore, our teaching content is not only to improve students' professional skills and knowledge in English major translation but also to take into account their actual problem-solving ability and to meet the requirements of the rapid development of the times. In the traditional teaching methods, English majors are usually taught by teachers in writing according to the specific problems of the students during the teaching process, and the students can correct where they are wrong [2].

A good English translation requires not only solid theoretical knowledge but also a lot of practical experience. However, at present, teachers of English majors in most colleges and universities lack practical experience. Therefore, there are deficiencies in teaching translation knowledge in the classroom. At the same time, most teachers do not get the training concepts, theoretical knowledge, and practical experience that keep pace with the times. Although they have a lot of translation skills and basic knowledge, they cannot 
combine theory and practice, which greatly affects them. The teaching effect is improved. Students' problem analysis ability, thinking ability, and problem solving ability cannot be cultivated accordingly. Therefore, in the new teaching methods, teachers should use guided and heuristic teaching methods to cultivate students' problem-solving thinking style and practical problem-solving ability. English translation does not have a unified answer, as long as it conforms to the actual situation and has the same meaning [3]. Translators for English majors still use traditional methods in teaching methods. The same as some other subjects, except that the teacher teaches some translation skills and experience in the classroom and does not use interactive teaching methods such as interactive teaching methods according to the needs of students and society. Some students cannot translate based on actual needs and subject knowledge. They can only learn from the direct experience of teachers and perform rough written translations. They cannot form their own unique translation skills and models, and the students' translation thinking ability cannot be explored and cultivated accordingly. Therefore, a single teaching method makes English majors uncomfortable and mechanically rigid when they are engaged in translation work.

\section{Related Work}

To improve the quality of translation teaching, it is necessary to conduct a better exploration of translation, including the definition of translation, the process of translation, and the characteristics of translation. The definition of translation should be the first topic of our discussion. Different people have different opinions on the definition of translation because they may have very different translated materials, different promotional purposes, and different audience needs. Therefore, many different translation strategies and methods and different answers have emerged with reference to the definition of translation.

Literature [4] proposed the concept of DLL, hereinafter referred to as (DDL), which aims to guide students to actively observe, discover, analyze, and summarize a large number of real corpora provided by the corpus, and use corpus retrieval technology to autonomously discover language features and language laws, so as to truly become the subject of learning. As soon as the concept of learning was put forward, it attracted widespread attention from the linguistics community and was soon introduced into the field of language teaching, and it also had a huge impact on translation teaching and research. Literature [5] conducted extensive discussions on the applicability of DDL in the field of translation and carried out empirical research on DDLbased translation teaching. The research found that DDL can help translators increase translation error rates and improve translation accuracy. Translation teaching research based on DDL started late in our country and focuses on speculative papers. It mostly demonstrates the feasibility and advantages of DDL from a macro perspective. There are relatively few empirical studies related to translation teaching for English majors. Research object: Literature [6] puts forward the social constructivist learning theory. The theory emphasizes the cognitive subject status of learners in the learning process and believes that knowledge is self-constructed by learners with the help of others and necessary learning resources in a certain context, that is, the social and cultural background. The enlightenment of this theory for university translation teaching is as follows: the learner is the center of translation teaching and the active constructor of translation knowledge, translation skills, and translation strategies; literature [7] learning is a process by which learners actively construct the meaning of knowledge, not a passive process of receiving information; learning is a process in which learners rely on teachers, peers, and other sources of information to cooperate in constructing meaningful knowledge. Literature [8] emphasizes learner-centered process, requiring teachers to use the corpus to create language learning situations with real corpus, guide learners to make full use of corpus resources, through observation, discussion, and analysis of a large number of the objective and true corpus, summarize the characteristics of language use, and proactively solve learning problems. Therefore, the social constructivist learning theory is consistent with the DDL concept and can provide theoretical guidance for constructing a DDL-based university translation teaching model. The literature [9] defines translation as "the act product of translation," and the literature [10] defines the definition as "an instance of an act, process, or translation; from one language to another. In the translation method, literature [11] claims that translation is a craft, including trying to replace written information and/or statements in one language with the same information and/or statements in another language. The DLL language learning process is divided into three stages by literature [12]: asking questions, classifying materials, and summarizing. The DLL language learning model differs from traditional teaching models in that the learner retrieves language materials from the corpus using a corpus retrieval tool, classifies the materials on the basis of classification, and finally, after studying the classified language learning materials, determines a specific set of rules for syntax and semantics. Literature [13] describes DLL language learning from the standpoint of the core link and believes that "this method avoids as much as possible the knowledge from the material to the teacher, and then from the teacher to the student." Participate directly in the creation of their own language meaning and use files. The term "interactive teaching" dates from the 1970s, and the literature [14] suggests that it emphasizes student-centered learning, in which students become masters of the information process rather than being stimulated. According to literature [15], two-way communication is at the heart of communication. Literature [16] considers interaction to be a dialogue between students and teachers.

Literature [17] pointed out that a major change in foreign language teaching is the emergence of many teaching modes similar to interactive teaching. Attention shifts from language form to language function. Not only can they increase their knowledge reserves, but they can also apply their knowledge to actual communication through interactive caching. Regarding the interactive teaching method 
based on the Internet, many education experts and English teachers widely believe that Internet technology can innovate the caching method and provide a more effective and convenient platform for teacher-student interaction. Literature [18] pointed out that the Internet technology platform is a new environment for translation teaching, which cannot be achieved in traditional teaching classrooms. This is a major innovation in the field of translation teaching and will surely achieve fruitful teaching results.

However, translation is more than just a matter of language; it also involves nonlinguistic factors like culture. As a result, the literature [19] defines translation as "a communication process and tool designed to promote the target language's sociopolitical, economic, or cultural development; its task is to completely transfer the logic and artistic reflection of reality in the source language to the target language." Translation is an important tool for people to communicate and spread cultural knowledge and a tool for social development. The history of civilization and social development cannot be seen without translation.

We can draw the following conclusions: translation is a process of thinking; translation involves the source language, target language, and the cultural boundary between two languages; translation is a means of information transmission. An in-depth understanding of translation is helpful to explore the application of DLL-based translation teaching in colleges and universities. Because translation is a process of thinking, teachers should pay more attention to the process of translation. Translation involves the interaction between teachers and students or between students. It is to exchange ideas and emotions, to spread culture and knowledge.

\section{DLL Theory}

Compared with the traditional college English teaching translation model, the DLL-based college English translation teaching model has the following main features, as shown in Figure 1.

This model embodies the learner-centered, fully mobilized learner's subjective initiative, pays attention to the learner's personalized learning, and emphasizes the learner's "self-management," "self-monitoring," and "self-evaluation" in the learning process. The language input mainly comes from the real language of the corpus. The corpus provides learners with real language materials (natural language), which can activate the real-world discourse and related knowledge in the learners' original cognitive structure, help the construction of the real language learning environment, and promote the learners' sense of meaning The construction of language. Learning emphasizes inductive summary, that is, a bottom-up learning method. Rather than prescriptive grammatical rules, learners can access a large amount of real language data through multimedia and corpus in this model's learning process. Every course has a distinct learning objective. The language learning purpose of a reading class, for example, is to provide students with a large number of reading materials in order to provide them with practical opportunities to use language, improve reading skills, and cultivate their comprehensive ability of induction, analysis, and inference [twenty two]. The nature of the course is largely determined by these teaching goals. As a result, each course must understand its own main teaching purpose in order to avoid becoming confused with other courses and to promote its own teaching rather than affecting the overall teaching effect. Teachers should also be aware that no single course can solve all of the issues. The goal of reading class is to teach students how to read and improve their comprehension skills, their ability to obtain useful information, their reading speed, their reading attention persistence, and their habit of reading in English. Other nonreading tasks can be skipped in the reading class and completed in other courses.

\section{Construction of Teaching Mode Based on DLL}

Traditional translation teaching mostly adopts a teachercentered top-down translation skills commenting model. We adjusted the DDL steps and tried to construct a bottomup, student-centered discovery-based translation teaching model, namely "(Teacher) corpus presentation-(student) observation and discussion-(student) report result-(teacher) guidance comment-(student) practice consolidation(student/teacher) comparative evaluation." The specific process is shown in Figure 2.

The traditional top-down teaching process of traditional translation teaching, in which theories are first followed by examples, is reversed in this teaching design. The real corpus (language input) is presented first, followed by questions and learners observing, discussing, and analyzing the corpus via cooperative learning. The teacher will then guide and explain in detail (language input), the learner will effectively combine translation theory and translation practice (language output), and students and teachers will then compare the translation practice text with the corpus text, analyze the gap, and students will eventually realize that they are actively constructing translation knowledge and skills. We not only ensure a sufficient amount of language input during the teaching process, but we also provide students with more language output practice.

How to solve the problem of small reading volume is a difficult problem that cannot be solved in the current reading class. The reasons are extremely complicated, including small class schedules and high test pressure. Teachers can guide students to carry out after-class knowledge points that appear in the text. To supplement and explore, try to provide a variety of feedback channels, mainly through three channels of display, evaluation, and assignment [20]. For example, teachers can set up some open questions about a certain knowledge point and read articles on related knowledge points after class, which not only provides each student with the opportunity to state their opinions in written or oral expression but also solves the problem of the learner's low reading volume. The current situation of narrow knowledge. The interactive task teaching method is fundamentally different from traditional teaching methods in that it is student-centered and focuses on cultivating students' language ability. Specific reading tasks provide 


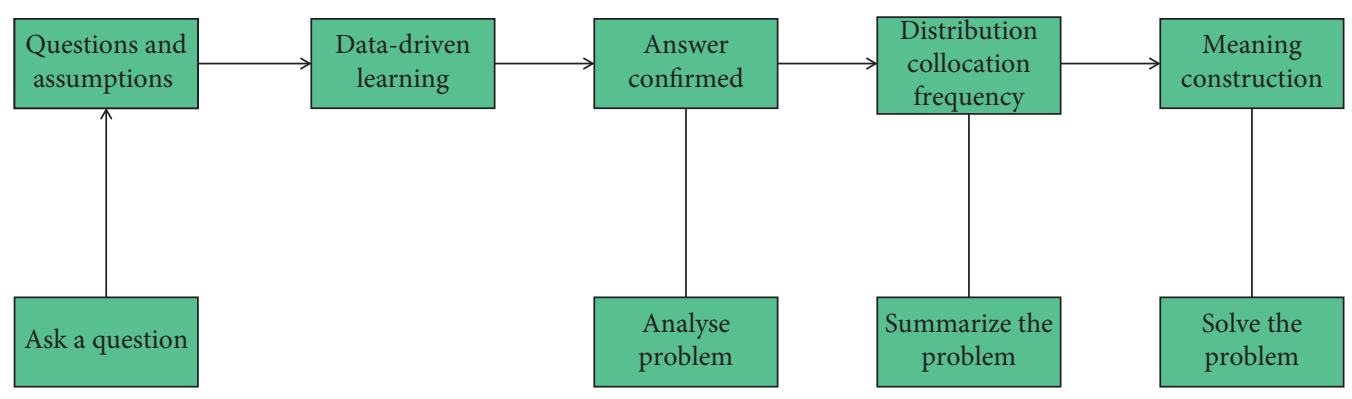

Figure 1: DLL-based college English translation teaching model.

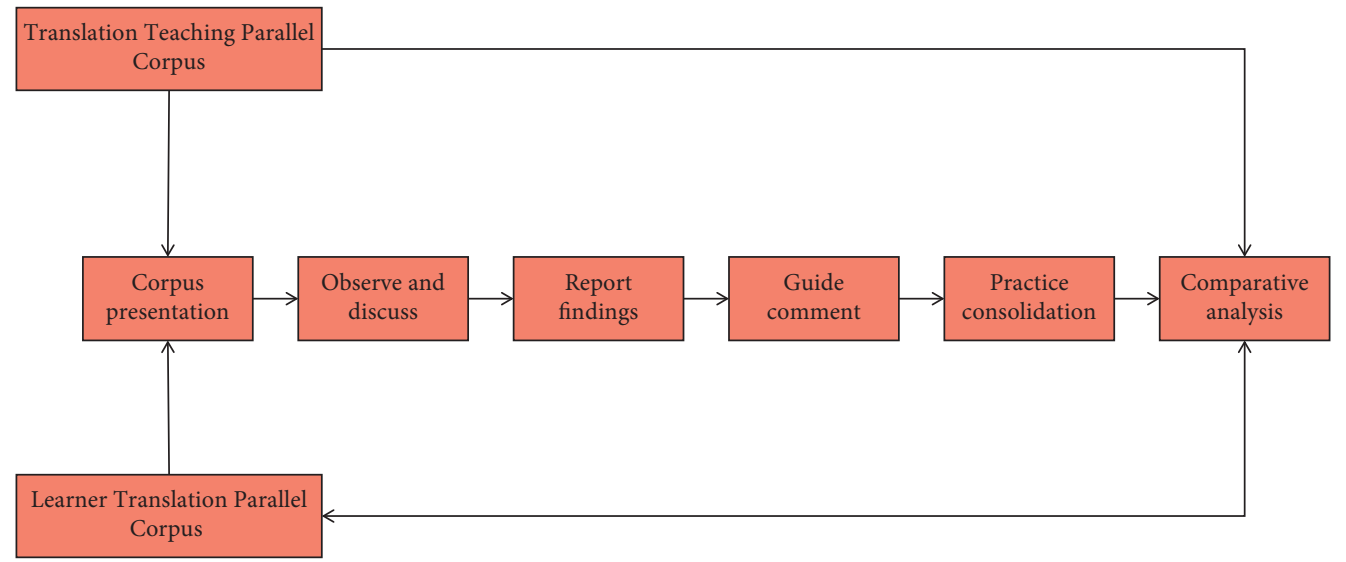

FIgURE 2: DLL college English translation teaching design.

students with motivation to learn. The learning process is the process of effectively completing specific tasks. The task's completion also denotes the outcomes of our instruction. However, task-based teaching in the field of foreign language teaching has only recently begun in our country, and it has yet to be promoted and effectively implemented in the teaching of English reading in higher vocational colleges. As a result, when considered in light of the current situation, the research on the benefits of the interactive task teaching method in reading class instruction has significant practical implications.

\section{The DLL English Translation Construction Method}

5.1. "Interactive" Methodology. This chapter introduces the methodology of empirical research in detail and discusses the feasibility and effectiveness of the application of the DLLbased interactive teaching method in English major translation teaching. This chapter is divided into four parts: research questions, research participants, and research. Finally, data collection and analysis are introduced [21].

The experiment lasted for 18 weeks. The pretest is conducted in the first week, and the posttest is conducted in the last week. The experiment was carried out in the remaining sixteen weeks. The eight tasks were completed during the six technical weeks. Two weeks, or 4 hours of homework teaching time, were introduced and displayed in the first teaching stage, which was 120 minutes per week; in the second teaching period of the second week, discussions, cooperation, feedback, and summary were conducted. At the same time, the same content is also entered into the CC.

A questionnaire survey was conducted prior to the experiment to fully understand the subjects' attitudes toward translation caching, traditional translation caching methods, and web-based interactive teaching methods. There are two parts to the questionnaire. The first section is about the participant's "personal information, such as gender, age, major, study length, and so on." A total of 12 questions are listed in the second section. Complete the questionnaire within 20 minutes, depending on your situation. The experiment was designed in a series of steps to ensure its feasibility and effectiveness. All subjects were given a questionnaire survey and a pretest prior to the teaching experiment. The collected data reflects their attitudes toward web-based interactive teaching methods and their level of translation. The teacher then used various teaching methods with EC and CC. A questionnaire survey was conducted among EC students at the end of the semester, and all participants were tested to determine their attitudes toward teaching methods and whether their translation skills had improved. An interview was conducted at the end of the semester to further investigate the students' attitudes toward the use of this new teaching method.

5.2. Predictive Test. In the first week of the semester, both EC and CC students must take the pretest. The content is selected from previous test papers and concise EnglishChinese Chinese-English translation courses. The exam 
should be invigilated by the same teacher who is not teaching within 90 minutes to draw their attention and ensure that they all take the exam. The teacher first claims that their scores will be used as a reference for their final assessment at the end of the semester.

More importantly, the content, quantity, structure, and difficulty of the pretest should be at the same level as the posttest. After all the essays are collected by the teacher, they are evaluated by the researcher and another experienced translation teacher in accordance with the same authoritative standard, and the result is two scores. The average of the two scores is used as the final score of each student.

In order to explore the effectiveness of the research and to ensure that there is no significant difference in the translation ability of EC and CC participants before the research, it is necessary to analyze the predicted results (see Tables 1 and 2).

The schematic diagram of the proportion of EC and CC scores is shown in Figure 3.

The pretest scores of EC and CC were compared prior to the experiment. It is important to see if EC and CC students are on the same level when it comes to translation skills. The EC and CC with the highest pretest scores are 82 and 84, respectively, and the EC and $\mathrm{CC}$ with the lowest pretest scores are 44 and 43, respectively, as shown in Figure 3. According to the data, the average score of the EC pretest is 62.03, which is similar to the CC score of 61.61. Based on the above comparison, it can be concluded that there was no significant difference in the translation proficiency of the two classes prior to the experiment.

The frequency distribution of pretest scores between EC and CC is shown in Figure 3. There are two students in the control class who have scores above 80 and two students who have scores below $80.70-79$ percentile 7 people, 5 people in the control class, 8 people in the control class, $60-69$ points, 10 people in the control class, 8 people in the control class, 50-59 points, 8 people, 10 people in the control class, 5 people under 50 points, 8 people, 10 people in the control class, 5 people under 50 points There are four control classes. The frequency distribution of scores reveals that before the experiment, the overall translation level between the two classes was similar. Because the subjects in the two classes had nearly identical translation levels prior to the experiment, the validity of the experiment can be concluded to be very high.

5.3. DLL Survey on Student Wishes. Both the experimental class and the control class conducted a prequestionnaire survey at the beginning of the semester. There are 12 questions in the questionnaire. There are five options at the end of each question, namely A, B, C, D. E. "A" expresses strong disagreement, " $\mathrm{B}$ " expresses disagreement, "C" expresses uncertainty, " $\mathrm{D}$ " expresses agreement, and ' $\mathrm{E}$ ' expresses strong agreement. The first is about students' main attitudes towards translation. Considering that students have participated in four activities through the application of web-based interactive teaching methods, namely preparation, presentation, discussion, and summary. Therefore,
TABLE 1: Descriptive statistics for the pretest between EC and CC.

\begin{tabular}{lcccc}
\hline Group & Number & Maximum & Minimum & Mean \\
\hline EC & 30 & 82 & 44 & 62.03 \\
CC & 31 & 84 & 43 & 61.61 \\
\hline
\end{tabular}

TABLE 2: The frequency distribution of scores in the pretest between EC and CC.

\begin{tabular}{lcccc}
\hline \multirow{2}{*}{ Marks } & \multicolumn{2}{c}{ Frequency } & \multicolumn{2}{c}{ Percentage } \\
& EC & CC & EC & CC \\
\hline Above 80 & 2 & 2 & 6.6 & 6.5 \\
$70-79$ & 7 & 5 & 23.3 & 16.2 \\
$60-69$ & 8 & 10 & 26.7 & 32.2 \\
$50-59$ & 8 & 10 & 26.7 & 32.2 \\
Below 50 & 5 & 4 & 16.7 & 12.9 \\
Total & 30 & 31 & 100 & 100 \\
\hline
\end{tabular}

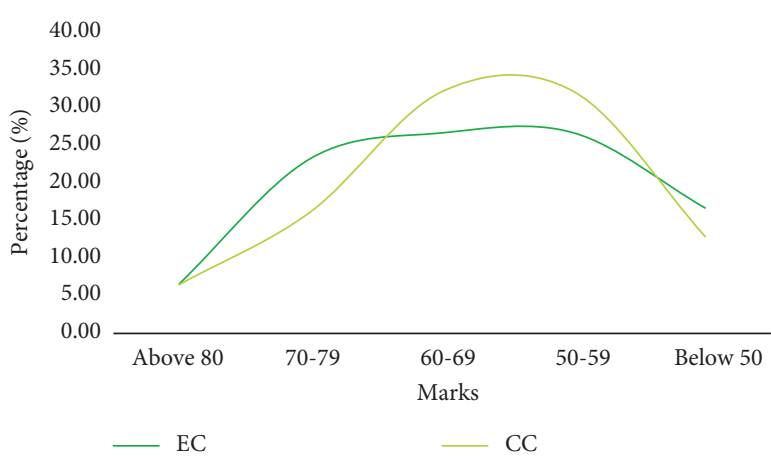

FIGURE 3: Schematic diagram of the proportion of EC and CC scores.

questions 2 to 12 are about students' attitudes towards the four stages of translation learning. The results and discussion will be detailed separately. The survey results are shown in Figure 4.

According to Figure 4, the first question is the student's main attitude towards translation interest, that is, I am interested in translation. More than half $(63.2 \%)$ of people are not interested in translation, and $18.4 \%$ think translation is interesting. Items $2 \sim 4$ are about students' attitudes towards interest in lesson preparation. From the data collected in items 2 and 3 , it can be seen that most $(56.8,65.4)$ do not like preparing lessons, let alone actively searching for relevant information or understanding the original text before class. They may think that this is just an extra burden on top of their heavy work, ignoring the importance of preparation. $63.9 \%$ of the participants thought that they would not correct the structure, content, grammar, and vocabulary problems in the first draft with their peers, as shown in item 4 .

Items 5 and 6 are about students' attitudes towards themselves in classroom presentations. According to the collected data, only $25.6 \%$ of the participants would show enthusiasm for the display of other groups, and 57.8 of them did not pay enough attention to the fruits of other groups. Of course, most of them (62.8\%) will not jot down the good points of other groups in time when listening or watching. They are not interested in sharing the opinions of others, even with so many shortcomings. 


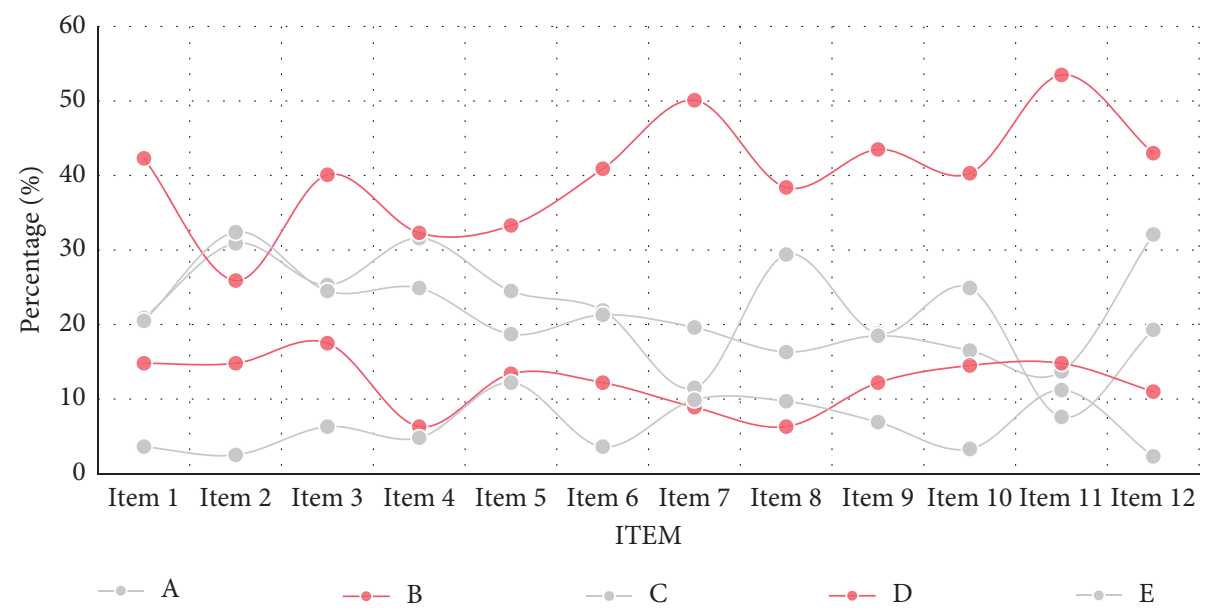

FIGURE 4: Descriptive statistics of EC and CC presurvey questionnaires.

In the discussion stage, items 7-9 represent students' attitudes toward their own interests. It is an important aspect of education, but the current situation is insufficient. For instance, itcm 7 "I try to listen to and accept the teachers' or classmates' suggestions for our group speech during the discussion." Only $18.8 \%$ of those polled agreed, and more than half $(61.6 \%)$ of those polled suggested speeches for their group from their teachers or classmates. Based on the data collected in item 8, only $16 \%$ of students will actively participate in discussions about the strengths and weaknesses of other groups. According to item 9 of the data collection, 62.3 percent of participants will not discuss their translation problems or difficulties with their teachers or peers. Only 19.1 percent of people think it is a good idea.

Items $10-12$ are about students' attitudes towards their interests in the summary stage. The content and structure of the translated manuscript are two important criteria for evaluating a manuscript. However, only $17.8 \%$ of students can summarize the advantages and disadvantages of the manuscript from the translation. Of course, students may have different views on the final standards provided by teachers, but only $26 \%$ of students like to communicate their different opinions with teachers or peers through Internet tools. The most important stage of learning is to summarize translation knowledge and mastered skills. In fact, only $12.3 \%$ of students can summarize what they have learned, which is not a good sign for them to study well.

5.4. Postquestionnaire Results and Discussion. The posttest questionnaire is conducted at the end of the semester, and only EC students will be asked to answer. The purpose of the questionnaire survey is to prove whether students' views on translation have changed significantly through a semester's learning. As shown in Figure 5, students' attitudes and interest in teaching methods have changed significantly compared with the data collected in the prediction questionnaire.

The results of the questions differ significantly from the results of the pretest questionnaire, which are shown in Figure 5, according to the researchers. These differences suggest that students' attitudes toward translation have shifted dramatically after enrolling in translation classes for a semester. When it comes to item 1, whether or not students are interested in translation, 62.3 percent of the subjects are satisfied, which is a significant change. EC participants became more active and interested in the presentations of other groups as a result of the data collected in items 5 and 6. For example, 72.9 percent of people will make every effort to listen to or watch the presentation, while only 20.9 percent will pay attention to other people's results. More importantly, the majority of them (72.2 percent) are prone to noticing others' advantages. They are displaying themselves. In other words, during the introduction stage, they become increasingly complex.

The purpose of this questionnaire is to understand the reading of students before the study. The questionnaire was conducted simultaneously in the experimental class and the control class. In this questionnaire, there are 7 questions about students' reading interests and self-confidence. The specific data are as follows.

It can be seen from the data in Table 3 and Figure 6 that most students do not like reading exercises, reading materials, and English articles. Most of them are not interested in reading. Interest is the best teacher. It occupies an important position in English reading and learning. If teachers can cultivate students' interest in reading, students' reading levels will improve.

From the data in Table 4 and Figure 7 , it can be seen that most students have insufficient confidence in completing reading tasks, obtaining high scores, and improving reading skills.

It can be seen that most students have no interest and confidence in English reading before applying for ITM. Then, the author will analyze the interest and confidence data of the students in the second questionnaire to understand whether there are any changes in the experimental class after receiving ITM.

5.5. Comparison of EC and CC Posttest Scores. After EC and $\mathrm{CC}$ use different teaching methods to teach, the scores of 


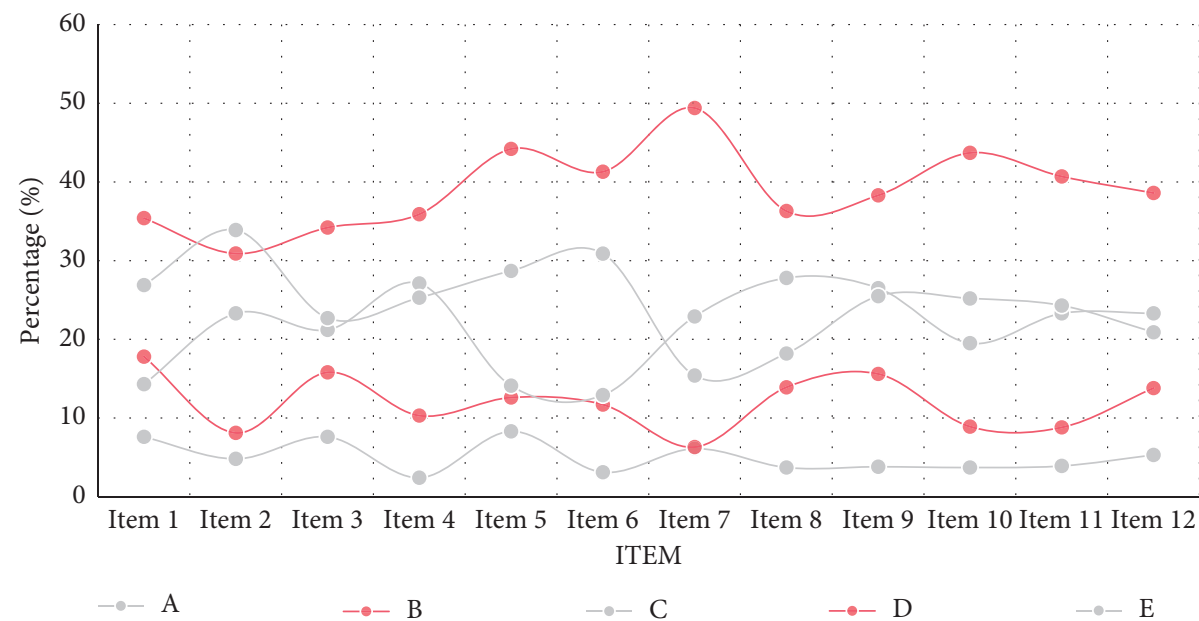

FIgURE 5: Descriptive statistics of the questionnaire (posttest) in EC.

TABle 3: Students' interest in English reading after the experiment.

\begin{tabular}{lcccc}
\hline Choices & Dislike & Just SO SO & Like better & Like a lot \\
\hline ATE & 25 & 44 & 16 & 15 \\
ATEA & 40 & 37 & 17 & 6 \\
ATERC & 42 & 31 & 19 & 8 \\
ATRM & 32 & 35 & 22 & 11 \\
\hline
\end{tabular}

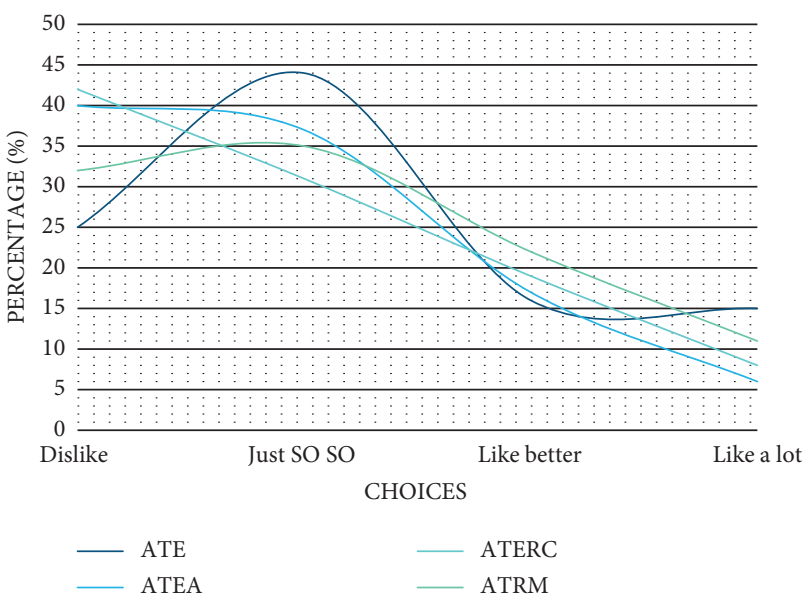

FIgURE 6: Students' interest in English reading after the experiment.

participants are shown in the following Table 5, and then detailed and respective discussions will be conducted.

In order to further test the effectiveness of the DLL-based interactive teaching model, the average scores of 14 individual items were compared (see Figure 8). The results are as follows:

It can be seen from Figure 9 that the application of interactive teaching methods based on data-driven learning in college English teaching by EC students is a new change to the status quo of traditional translation teaching. It is based on constructive learning theory and collaborative learning theory. The basics are taught from the perspective of cognitive principles. It is proposed to break through the limitations of traditional translation teaching methods, such as the limitations of teaching materials and language phenomena, and ignore the main body of students. Research shows that this teaching method is indeed effective in improving students' translation ability and stimulating students' interest in translation. Therefore, the following enlightenments are put forward.

The teaching model is highly evaluated in the following aspects: friendship development (4.37), information sharing (4.37), peer evaluation and correction (4.26), inspiration (4.21), the usefulness of resources (4.16), confidence (4.05), and criticism Sexual thinking (4.05). At the same time, most students urgently need more scaffolding (4.37) and the guidance of teachers, experts, and experienced students' translators. The interaction on the platform encourages student personalization and collaboration. Some students reported that it is easy to express ideas on the platform, especially for those students who are introverted. At the same time, the students actively cooperate to solve translation problems. Many students explained that the interactive platform promoted their friendship and inspiration. They are willing to share their solutions and try to find reasons for their decisions so as to cultivate their critical thinking. More importantly, through information sharing and peer evaluation, they increased the literature resources and assessed the appropriateness of the information, thereby improving their information search capabilities. However, the interactive effect of the new model does not show a significant advantage compared with the traditional method (3.84). There is still a lot of room for improvement in the new model, especially in the following areas: the usefulness of 
TABLE 4: Students' confidence in English reading after the experiment.

\begin{tabular}{lcccc}
\hline Choices & Be very confident & Be confident & Be not confident & Be not confident at all \\
\hline HCTFTRT & 15 & 20 & 46 & 19 \\
HCTGHS & 10 & 18 & 43 & 29 \\
HCIIRL & 9 & 16 & 45 & 30 \\
\hline
\end{tabular}

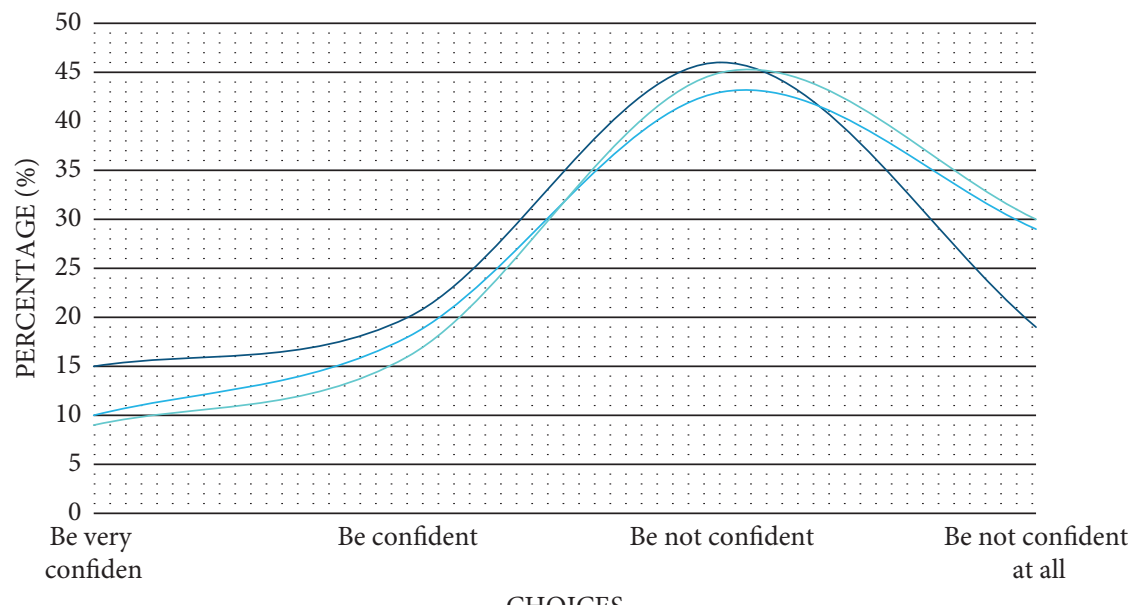

CHOICES

- HCTFTRT

HCTGHS

HCIIRL

Figure 7: Students' confidence in English reading after the experiment.

TABle 5: The frequency distribution of scores in the posttest between EC and CC.

\begin{tabular}{|c|c|c|c|c|}
\hline \multirow{2}{*}{ Marks } & \multicolumn{2}{|c|}{ Frequency } & \multicolumn{2}{|c|}{ Percentage } \\
\hline & $\mathrm{EC}$ & $\mathrm{CC}$ & $\mathrm{EC}$ & $\mathrm{CC}$ \\
\hline Above 80 & 7 & 3 & 23.3 & 9.67 \\
\hline $70-79$ & 7 & 6 & 23.3 & 19.3 \\
\hline $60-69$ & 9 & 9 & 30 & 29.0 \\
\hline $50-59$ & 6 & 10 & 20 & 32.2 \\
\hline Below 50 & 1 & 3 & 3.4 & 9.8 \\
\hline Total & 30 & 31 & 100 & 100 \\
\hline
\end{tabular}

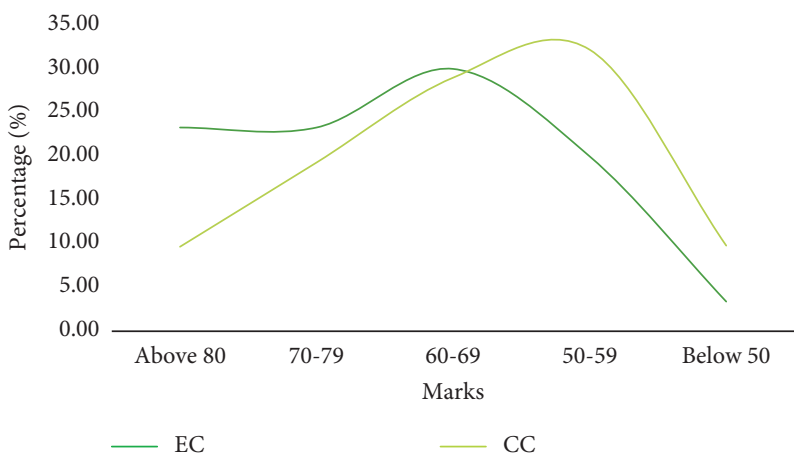

FIgURE 8: Schematic diagram of the proportion of EC and CC scores. 


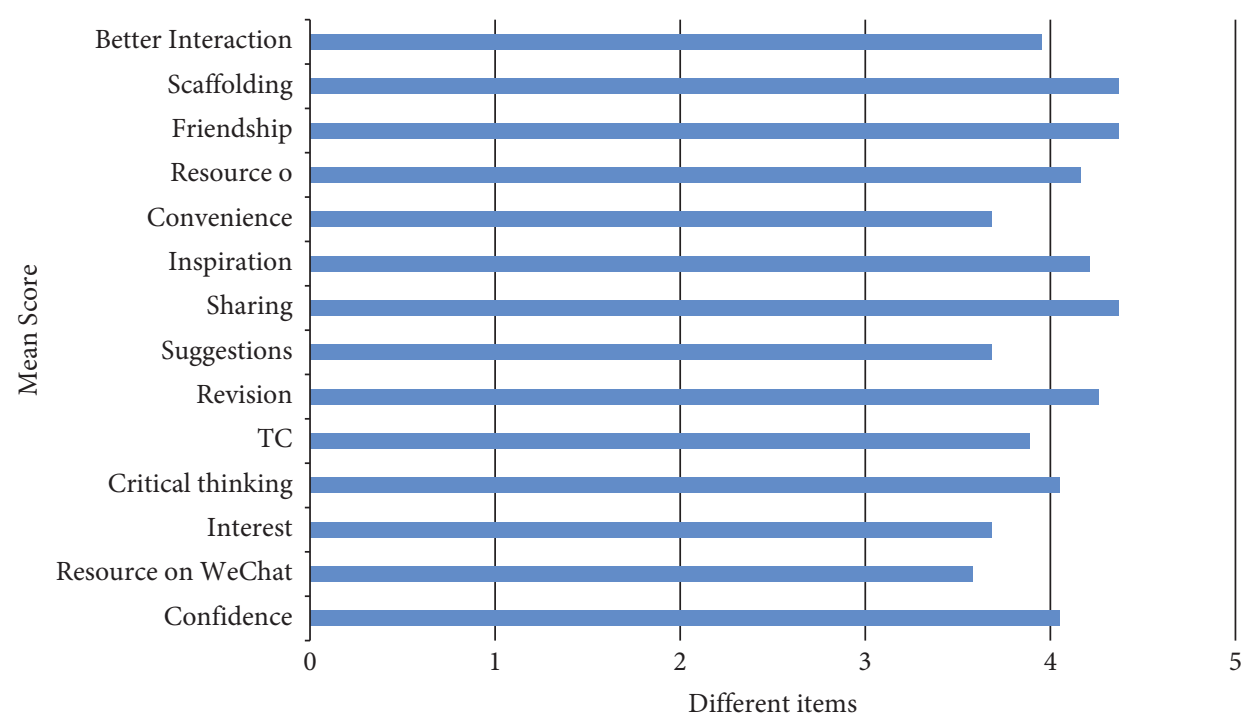

Figure 9: Mean score of students' evaluation of the new model.

the WeChat public platform resources (3.58), increased interest (3.68), encouraged students to make suggestions in small discussion groups (3.68), and improved the interactive platform Convenience (3.68), improve student TC (3.89).

\section{Conclusions}

This study focuses on the practical application of translation parallel DLL and learner parallel DLL in college English translation classroom teaching and the development of a DLL teaching design appropriate for English major translation. However, it must be acknowledged that there are still barriers to the promotion of DDL-based translation teaching design. The use of an interactive teaching method based on data-driven learning in college English classes represents a significant departure from the status quo of traditional translation instruction. It teaches from the perspective of cognitive principles and is based on constructive learning theory and collaborative learning theory. It is proposed that traditional translation teaching methods be broken through, such as the limitations of teaching materials and language phenomena, and that the main body of students is ignored. According to research, this teaching method is effective in improving students' translation abilities and piqueing their interest in the field of translation. As a result, the following observations are made.

To begin with, because there is no English-Chinese translation DLL suitable for English professional translation teaching, teachers must create their own corpus based on student needs, language level, and teaching goals, as well as maintain and update it, which is time-consuming and laborious. Second, the construction of DLL necessitates a solid understanding of computers, networks, and DLL, which makes many teachers who are unfamiliar with or have a limited understanding of DLL fearful of difficulties and hesitant to try new teaching methods and teaching methods. Third, translation courses for English majors are shorter and provide more training. DLL and its search function are difficult to use, and students cannot search various DLLs using word index software on their own. As a result, we believe that, in the face of English majors, DDL-based translation teaching still requires teachers to screen corpus, preventing students from achieving true autonomy. Fourth, English majors' English proficiency is uneven, and their understanding and analysis of corpus are superficial due to a lack of systematic language learning, making it difficult to think deeply about language and translation issues. Is translation education covered by DLL? It is still unclear whether the expected teaching effect can be achieved. We will also conduct empirical research on translation teaching with English majors as the research subjects and provide references to support DDL-based translation teaching models.

\section{Data Availability}

The data used to support the findings of this study are included within the article.

\section{Conflicts of Interest}

The author declares that there are no conflicts of interest.

\section{Acknowledgments}

The work was supported by the Heilongiiang Bayi Agricultural University (Heilongjiang Bayi Agricultural University Support Program for San Heng San Zong), "Research on Effective Communication of Interdisciplinary Research Achievements in Linguistics Based on New Liberal Arts" (Project Number: RRCPY202008). 


\section{References}

[1] X. Liu and W. Zhang, "The application of data-driven learning in college English translation teaching," Modern Educational Technology, vol. 4, pp. 55-59, 2021.

[2] Y. Ling, "Research on corpus-based data-driven model in English self-access learning," Journal of Shaoguan University, vol. 12, pp. 1-3, 2012.

[3] L. Flowerdew, "Data-driven learning and language learning theories," Multiple affordances of language corpora for datadriven learning, vol. 69, pp. 15-36, 2015.

[4] Y. Lu, "The construction of CAT interactive translation teaching mode in the translation workshop environment: taking Hubei University of Arts and Sciences (Translation) as an example," Journal Of Beijing City University, vol. 1, no. 1, pp. 83-86, 2013.

[5] S. Liang, "Exploration of exhibition translation teaching under data-driven learning mode," Journal of Chongqing University of Education, vol. 4, no. 4, pp. 113-117, 2017.

[6] A. Thomas, A. Menon, J. Boruff, A. M. Rodriguez, and S. Ahmed, "Applications of social constructivist learning theories in knowledge translation for healthcare professionals: a scoping review," Implementation Science: Iscus, vol. 9, no. 1, pp. 54-20, 2014.

[7] C. Liu, "Research on medical translation teaching path driven by data and tasks-taking "methods" translation teaching as an example," Journal of University of Shanghai For Science and Technology Social Science, vol. 1, no. 1, pp. 12-16, 2019.

[8] Li Ge, "DDL concept and professional English teaching of translation," Journal of Taiyuan Urban Vocational College, vol. 10, no. 10, pp. 155-157, 2014.

[9] X. Gong, "DDL translation teaching based on online EnglishChinese parallel corpus-take English passive sentence translation teaching as an example," Journal of Xihua University Philosophy Social Sciences, vol. 5, no. 5, pp. 107-112, 2016.

[10] Li Xiang, "Research on the application of English and Chinese corpus," Journal of North China University of Technology, vol. 4, no. 4, pp. 60-64, 2011.

[11] Z. Zhou, "Exploration of the "dual drive" model of English teaching based on bilingual corpus," Journal of Chengdu Normal University, vol. 10, no. 10, pp. 70-74, 2014.

[12] Y. Wu, "Research on interactive model of English translation based on data mining," International Journal for Engineering Modelling, vol. 31, no. 1, pp. 273-279, 2018.

[13] J. Zhou, "Construction of artificial intelligence-based interactive oral English teaching platform based on application problems of present intelligent products," IOP Conference Series: Materials Science and Engineering, vol. 569, no. 5, Article ID 052055, 2019.

[14] J. Qu, "Research on mobile learning in a teaching information service system based on a big data driven environment," Education and Information Technologies, vol. 26, no. 5, pp. 6183-6201, 2021.

[15] Y. Cheng, J. Peng, X. Gu et al., "An intelligent supplier evaluation model based on data-driven support vector regression in global supply chain," Computers \& Industrial Engineering, vol. 139, pp. 105834.1-105834.11, 2020.

[16] D. Rajpathak and S. De, "A data- and ontology-driven text mining-based construction of reliability model to analyze and predict component failures," Knowledge and Information Systems, vol. 46, no. 1, pp. 87-113, 2016.

[17] Q. Zhou, S. Lu, Y. Wu, and J. Wang, "Property-oriented material design based on a data-driven machine learning technique," The Journal of Physical Chemistry Letters, vol. 11, no. 10, pp. 3920-3927, 2020.

[18] V. Pranathi, G. R. Reddy, G. Sunil, D. Raghava Kumari, and B. Jamalpur, "A comprehensive study on the various applications of deep learning," IOP Conference Series: Materials Science and Engineering, vol. 981, no. 2, Article ID 022045, 2020.

[19] Q. Fang, "Construction and application of internal medicine teaching interactive course based on 5-star instructional model," International Journal of Emerging Technologies in Learning (IJET), vol. 14, no. 3, p. 122, 2019.

[20] S. Tseranidis, N. C. Brown, and C. T. Mueller, "Data-driven approximation algorithms for rapid performance evaluation and optimization of civil structures," Automation in Construction, vol. 72, no. 3, pp. 279-293, 2016.

[21] Y. Liu, Y. Song, Y. U. Jiayue, Y. Xie, Y. Wang, and X. Zeng, "Big-data-driven model construction and empirical analysis of SMEs credit assessment in China," Procedia Computer Science, vol. 147, pp. 613-619, 2019. 